\title{
EMPREGO DE DILUENTES NA DETERMINAÇÃO DA ATIVIDADE CELULOLÍTICA DO CALDO FERMENTADO DE Xanthomonas arboricola pv pruni
}

\author{
F. G. A. GAUTÉRIO ${ }^{1}$, K. L. MACAGNAN ${ }^{2}$, R. F. TEIXEIRA ${ }^{1}$, A. S. MOREIRA ${ }^{2}$ e C. T. \\ VENDRUSCOLO ${ }^{2}$ \\ ${ }^{1}$ Universidade Federal do Pampa, Bagé, RS, Engenharia de Alimentos \\ ${ }^{2}$ Universidade Federal de Pelotas, Pelotas, RS, Centro de Desenvolvimento Tecnológico \\ E-mail para contato: fernandagauterio@unipampa.edu.br
}

\begin{abstract}
RESUMO - Bactérias do gênero Xanthomonas produzem inúmeras enzimas hidrolíticas, incluindo celulases. Estes microrganismos também fermentam aerobicamente açúcares como a sacarose ou glucose, produzindo um heteropolissacarídeo denominado xantana. O acúmulo de xantana durante o processo fermentativo provoca um incremento acentuado da viscosidade do caldo fermentado. Por este motivo, torna-se necessário empregar um agente capaz de reduzir a viscosidade do meio e permitir a remoção celular para posteriores estudos, quando isto for necessário. O presente trabalho teve como objetivo a avaliação da influência de diferentes diluentes do caldo fermentado de Xanthomonas arboricola pv pruni cepa 101 para a determinação da atividade celulolítica. Nesta análise, foram empregados como diluentes, na proporção de $1: 1(\mathrm{v} / \mathrm{v})$ : solução salina $0,89 \%$, água destilada e tampão citrato $\mathrm{pH}$ 4,8 e 7,0. A solução salina conduziu a uma redução na viscosidade, sendo mais eficiente na remoção das células de Xanthomonas no caldo fermentado; além de permitir uma maior atividade celulolítica; sugerindo ser este o melhor diluente entre os testados.
\end{abstract}

\section{INTRODUÇÃO}

Xantana é um heteropolissacarídeo extracelular produzido por bactérias do gênero Xanthomonas (Lilly et al., 1958 e Sloneker e Jeanes, 1962). Todas as espécies deste gênero são consideradas fitopatogênicas, infectando vários gêneros. Esta capacidade é dependente de vários fatores, os quais incluem a síntese de enzimas extracelulares, tais como as celulases, e também a produção do exopolissacarídeo xantana (Tang et al., 1981 e Hayward, 1993).

Xanthomonas campestris pv campestris produz xantana abundantemente, razão pela qual é amplamente utilizada industrialmente para este fim (Sutherland, 1993). No entanto, Xanthomonas arboricola pv pruni também tem sido considerada eficiente produtora de xantana (Vendruscolo et al., 2000; Moreira et al., 2001 e Alves et al., 2009), um polissacarídeo microbiano de grande significância comercial devido as suas propriedades reológicas interessantes (Sutherland, 2001) para as indústrias alimentícia, farmacêutica e petrolífera. É o único polímero que pode apresentar, simultaneamente, alta viscosidade, mesmo em baixas concentrações, pseudoplasticidade e resistência térmica a, no mínimo 


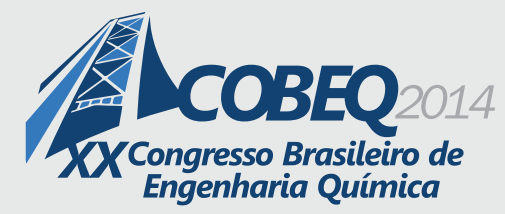

19 a 22 de outubro de 2014

Florianópolis/SC

$65^{\circ} \mathrm{C}$; além de ser estável em ampla faixa de pH e temperatura (Sutherland, 1999 e Born et al., 2002).

Exopolissacarídeos microbianos podem ser considerados substratos para uma ampla gama de enzimas, a maioria dos quais são altamente específicos. Bactérias produtoras de xantana sintetizam uma série de enzimas extracelulares, como celulases, que podem degradar o biopolímero (Sutherland, 1982). De acordo com Dow et al. (2003), a proteína extracelular, principalmente em Xanthomonas campestris, é uma endo- $\beta$-1,4-glucanase. Esta enzima é uma celulase que cliva a cadeia de celulose em pontos aleatórios internos, produzindo mais cadeias finais onde exo- $\beta$-glucanase pode atuar (Eriksson e Pettersson, 1975 e Wood e McCrae, 1975). Existem também enzimas intracelulares, localizadas no periplasma; caso ocorra a lise celular durante a cultura, estas enzimas podem ser liberadas ao meio extracelular e provocarem a degradação do polímero (Sutherland, 2001).

Na produção de xantana, a viscosidade do caldo aumenta pelo acúmulo do polímero no meio de cultivo. Assim, para separar as células do restante do caldo fermentado e estudar as enzimas extracelulares, torna-se necessário o uso de diluentes para possibilitar esta operação mediante centrifugação. Por esta razão, o presente trabalho teve como objetivo a avaliação da influência de diferentes diluentes do caldo fermentado de Xanthomonas arboricola pv pruni cepa 101 para a determinação da atividade celulolítica.

\section{MATERIAL E MÉTODOS}

\subsection{Multiplicação celular e condução do processo fermentativo}

$X$. arboricola pv pruni 101 foi empregada para a produção do inóculo em incubador agitador rotativo (modelo B. Braun Biotech International ${ }^{\circledR}$ ) durante $24 \mathrm{~h}$, conforme patente WO/2006047845 (Universidade Federal de Pelotas, 2006). As fermentações foram do tipo submersa, em fermentador (modelo Biostat B de 5L, B. Braun Biotech International ${ }^{\circledR}$ ) de 5L, com volume útil de 3L, por 72h (WO2006047845). O pH foi ajustado inicialmente em 7,0 e não mais controlado durante o processo.

\subsection{Remoção celular}

As células foram separadas do caldo fermentado por centrifugação (47 $810 \mathrm{x} \mathrm{g}$, centrífuga Sorvall ${ }^{\circledR}$ RC modelo 6). Para melhorar a separação de células, diferentes diluentes foram empregados para reduzir a viscosidade do caldo fermentado: água destilada; solução salina $0,89 \%$ (v/v); e tampões citrato de sódio ( $\mathrm{pH} 4,8$ e 7,0), na proporção de 1:1 (v/v). As células foram lavadas com os mesmos diluentes, re-centrifugadas e secas em estufa a $56^{\circ} \mathrm{C}$, até peso constante e este foi convertido em gramas de massa celular seca por litro de caldo fermentado. Todas as amostras (caldo fermentado com e sem diluição) foram centrifugadas com o mesmo volume total. Essas determinações foram realizadas em triplicata e os resultados foram tratados estatisticamente por Análise de Variância e Teste de Tukey, com um nível de 95\% de confiança ( $<<0,05)$.

\subsection{Determinação da viscosidade do caldo fermentado}

A determinação da viscosidade foi empregada para confirmar a eficiência da separação 
celular. Para isto, as viscosidades dos caldos fermentado diluídos foram determinadas em reômetro (HAAKE $®$ modelo RheoStress RS150) no modo rotativo a $25^{\circ} \mathrm{C}$, utilizando um sistema de cilindro coaxial, sensor DG 41 e taxa de cisalhamento de $100 \mathrm{~s}^{-1}$. As medições de viscosidade foram realizadas em triplicata e os resultados foram tratados estatisticamente por Análise de Variância e Teste de Tukey, com um nível de $95 \%$ de confiança $(\mathrm{p}<0,05)$.

\subsection{Determinação da atividade celulolítica}

Oito combinações de diluente e pH foram usadas para avaliar a atividade celulolítica no caldo fermentado (Tabela 1). A atividade foi determinada espectrofotometricamente pelo método do ácido dinitrossalicílico (DNS) (Miller 1959, modificado) a 540nm (HITACHI@, modelo L-180), utilizando $1 \%(\mathrm{~m} / \mathrm{v})$ de carboximetilcelulose (Synth $($ ) como o substrato diluído em tampão de citrato de sódio (pH 4,8 ou 7,0). As medições de atividade celulolítica foram realizadas em triplicata e os resultados foram tratados estatisticamente por Análise de Variância e Teste de Tukey, com um nível de 95\% de confiança $(\mathrm{p}<0,05)$.

Tabela 1 - Combinações de diluentes do caldo fermentado e pH na determinação da atividade celulolítica

\begin{tabular}{cc}
\hline Diluentes $^{\mathrm{a}}$ & $\mathrm{pH}^{\mathrm{b}}$ \\
\hline Água destilada (A) & 4,8 \\
& 7,0 \\
Solução salina (S) & 4,8 \\
& 7,0 \\
Tampão citrato de sódio pH 4,8 (T4,8) & 4,8 \\
Tampão citrato de sódio pH 7,0 (T7,0) & 7,0 \\
& 7,8 \\
\hline
\end{tabular}

${ }^{\text {a }}$ Diluentes do caldo fermentado

${ }^{\mathrm{b}}$ valor do $\mathrm{pH}$ de reação empregado na determinação da atividade celulolítica

\section{RESULTADOS E DISCUSSÃO}

O caldo fermentado de Xanthomonas arboricola pv pruni 101 torna-se altamente viscoso devido à produção do biopolímero xantana de elevada viscosidade, o que dificulta separação das células deste meio. A diluição torna-se necessária para melhorar a eficiência de remoção celular por centrifugação e, consequentemente, a atividade celulolítica pode ser determinada sem efeitos prejuízos. A água destilada é considerada como um diluente clássico, além de ser mais econômico; a solução salina é empregada rotineiramente para a recuperação da biomassa por centrifugação durante a etapa de lavagem; e o tampão citrato de sódio é recomendado na determinação da atividade celulolítica de acordo metodologia proposta por Miller (1959). Com relação aos valores de pH do tampão citrato de sódio empregado como diluente no presente trabalho, o pH 4,8 foi utilizado por ser indicado pelo método padrão para a determinação da atividade da celulase extracelular (Miller, 


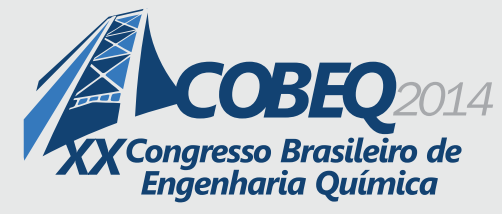

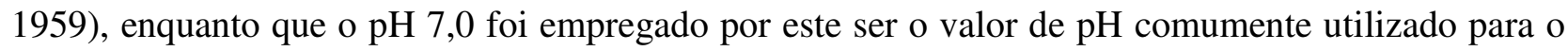
caldo fermentado durante o processo fermentativo para produzir xantanas mais viscosas, conforme García-Ochoa et al. (2000).

Os resultados de massa celular seca e viscosidade dos caldos fermentados diluídos auxiliam na discussão da eficiência do emprego dos diluentes do caldo fermentado, conforme Tabela 2. Em todas as amostras de caldo fermentado diluídos constatou-se uma melhoria significativa na remoção celular. Observou-se uma correlação inversa entre a viscosidade do caldo fermentado e remoção de células. $\mathrm{O}$ emprego de solução salina como diluente proporcionou maior redução da viscosidade do caldo fermentado e, consequentemente, uma maior remoção celular quando comparado com os demais diluentes, como pode ser visualizado aumento no valor da massa celular seca (Tabela 2).

Tabela 2 - Massa celular seca e viscosidade dos caldos fermentados diluídos (taxa de cisalhamento de $100 \mathrm{~s}^{-1}, 25^{\circ} \mathrm{C}$ )

\begin{tabular}{ccccc}
\hline $\begin{array}{c}\text { Diluentes do caldo } \\
\text { fermentado }\end{array}$ & $\begin{array}{c}\text { Massa celular } \\
\text { seca }\left(\mathrm{g} . \mathrm{L}^{-1}\right)\end{array}$ & $\begin{array}{c}\text { Incremento de } \\
\text { remoção de massa } \\
\text { celular seca } \\
(\%)\end{array}$ & $\begin{array}{c}\text { Viscosidade } \\
\text { do caldo } \\
\text { fermentado } \\
\text { diluído } \\
(\mathrm{mPa} . \mathrm{s})\end{array}$ & $\begin{array}{c}\text { Redução de } \\
\text { viscosidade do } \\
\text { caldo fermentado } \\
\text { diluído (\%) }\end{array}$ \\
\hline $\begin{array}{c}\text { Controle } \\
\text { Água destilada (A) }\end{array}$ & $1,3^{* * \mathrm{~d}}$ & - & $60,2^{\mathrm{a}}$ & - \\
Solução salina (S) & $1,6^{\mathrm{b}, \mathrm{c}}$ & $23,1^{\mathrm{c}}$ & $19,9^{\mathrm{c}}$ & $66,9^{\mathrm{c}}$ \\
Tampão citrato de & $2,1^{\mathrm{a}}$ & $61,5^{\mathrm{a}}$ & $17,2^{\mathrm{e}}$ & $71,4^{\mathrm{a}}$ \\
sódio pH 4,8 (T4,8) & $1,5^{\mathrm{c}}$ & $15,4^{\mathrm{d}}$ & $20,7^{\mathrm{b}}$ & $65,6^{\mathrm{d}}$ \\
Tampão citrato de & $1,8^{\mathrm{b}}$ & $38,5^{\mathrm{b}}$ & $18,4^{\mathrm{d}}$ & $69,4^{\mathrm{b}}$ \\
sódio pH 7,0 (T7,0) & & & & \\
\hline
\end{tabular}

* Caldo fermentado não diluído

${ }^{* *}$ Valor original (2,6 g.L $\mathrm{L}^{-1}$ no caldo fermentado não diluído) foi convertido para equivalência com as demais amostras em termos de volume de caldo fermentado na etapa da centrifugação

Letras minúsculas distintas na mesma coluna diferem estatisticamente pelo Teste de Tukey com $\mathrm{p}<0,05$

Xantana funciona como um agente espessante e estabilizador de suspensões, trabalhando contrariamente à força centrífuga e, por esta razão, reduz a eficiência da centrifugação. O aumento na remoção de celular foi devido à redução na concentração de xantana e, consequentemente, na viscosidade do caldo fermentado. No entanto, o tipo de diluente utilizado influenciou significativamente a viscosidade. Estruturalmente, a xantana comercial é composta por uma cadeia celulósica formada por moléculas de glicose unidas por repetitivas ligações do tipo $\beta(1-4)$ e uma cadeia lateral com duas unidades de manose alternadas por uma de ácido glucurônico.

Em algumas moléculas de manose internas, ligadas à cadeia principal, e externas pode ser observada a presença dos ácidos acético e pirúvico, respectivamente (Sloneker e Jeanes 1962; Jansson et al 1975); e a estes resíduos ácidos podem se ligar cátions oriundos de sais de sódio, potássio, cálcio e magnésio. Esses cátions podem ser provenientes do meio de cultura utilizado para a 


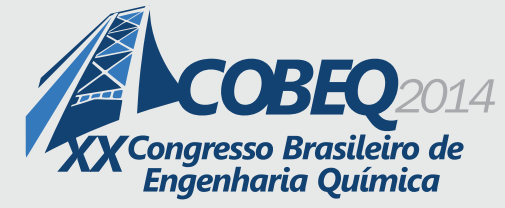

19 a 22 de outubro de 2014

Florianópolis/SC

produção do polímero ou podem ser adicionados para controle do $\mathrm{pH}$ do meio de fermentação (García-Ochoa et al., 2000 ) ou, até mesmo, adicionados após o processo fermentativo, como, por exemplo, na diluição do caldo fermentado, tais como solução salina e tampão citrato, como realizado no presente estudo.

Para Ross-Murphy et al.(1983) e Rinaudo (2001), as propriedades da xantana podem ser influenciadas pela natureza e concentração de sais adicionados. De acordo com Katzbauer (1998), Garcia-Ochoa et al. (2000), Sutherland (2001) e Born et al. (2002), a presença ou a adição de eletrólitos em soluções de xantana influencia as propriedades químicas e o comportamento reológico, especialmente sobre a viscosidade do polímero. Uma concentração muito elevada de sal pode causar mudança conformacional na molécula do polímero, reduzindo o volume hidrodinâmico e, consequentemente, a viscosidade (Carrington et al.,1996 e Pelletier et al., 2001). No presente estudo, a redução da viscosidade foi desejável.

Pela Figura 1 pode-se observar que a atividade celulolítica determinada em $\mathrm{pH}$ 4,8 foi menor, e não apresentou diferença significativa entre os diluentes (água destilada, solução salina e tampão citrato de sódio) testados neste $\mathrm{pH}$. Em pH 7,0 de reação não houve diferença significativa entre as atividades enzimáticas determinadas a partir dos diluentes água e tampão citrato $\mathrm{pH} 4,8$; sendo significativamente diferentes dos demais diluentes empregados (solução salina e tampão citrato $\mathrm{pH}$ 7,0). A atividade mais elevada foi alcançada empregando solução salina, determinada em pH 7,0 de reação para determinação da atividade celulolítica.

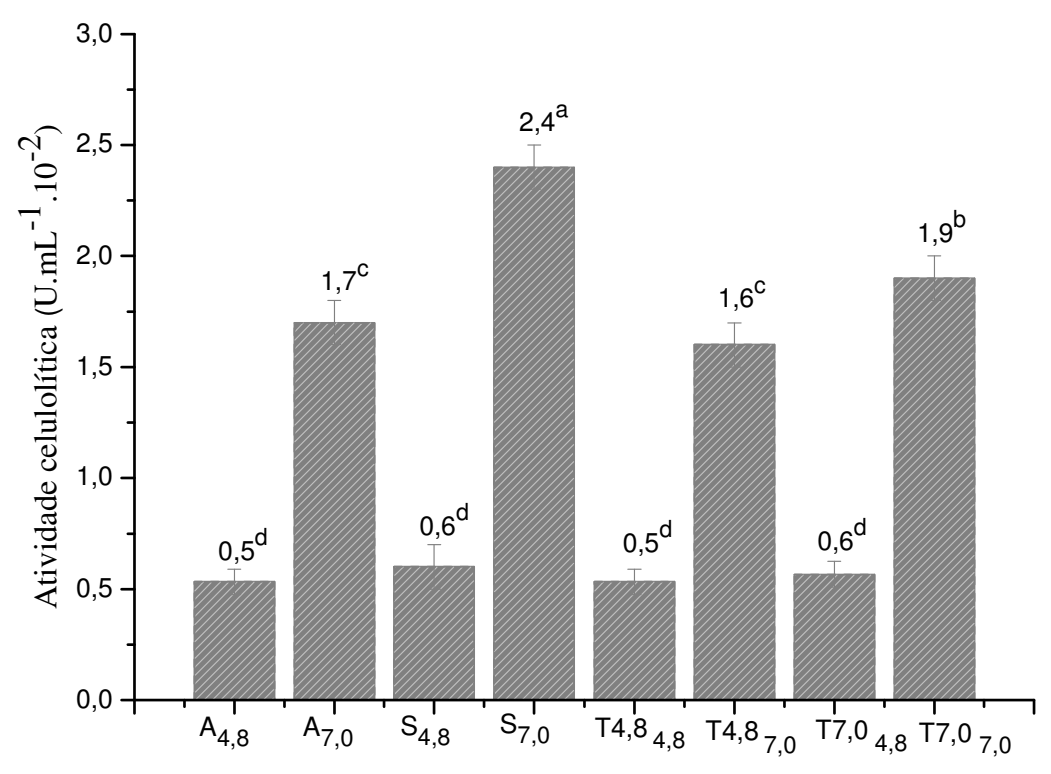

Figura 1 - Avaliação da atividade celulolítica no caldo fermentado por $X$. arboricola pv pruni 101 diluído com água destilada (A), solução salina (S), tampão citrato de sódio pH 4,8 (T4,8) ou tampão citrato de sódio pH 7,0 (T7,0). Os valores sobrescritos $(4,8$ e 7,0) nos diluentes abreviados como A, $\mathrm{S}$ e T referem-se ao valor do $\mathrm{pH}$ de reação, ou seja, valor de $\mathrm{pH}$ empregado na determinação da 


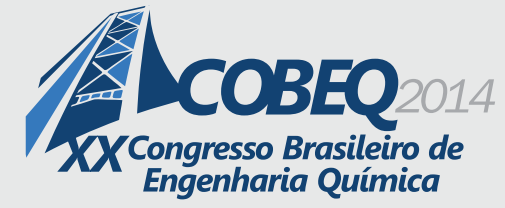

atividade celulolítica. * Letras distintas diferem estatisticamente pelo Teste de Tukey com $\mathrm{p}<0,05$.

A solução salina, além de ser considerada um diluente econômico, ocasionou redução da viscosidade do caldo fermentado sem exercer prejuízos à determinação da atividade celulolítica. A redução da viscosidade pôde auxiliar na determinação da atividade enzimática. Desta forma, solução salina como diluente juntamente empregando o pH 7,0 da reação para determinação da atividade enzimática constituem as melhores condições, dentre as testadas, para a determinação da atividade extracelular da celulase no caldo fermentado por X. arboricola pv pruni.

\section{CONCLUSÃO}

Solução salina mostrou ser o diluente mais eficiente do caldo fermentado de Xanthomonas arboricola pv pruni 101 para a remoção celular e subsequente determinação da atividade celulolítica. A redução na viscosidade do caldo fermentado incrementou a atividade celulolítica.

\section{REFERENCIAS}

ALVES, F. G.; KLAIC, P. M. A.; RODRIGUES, A. A.; MOREIRA, A. S.; VENDRUSCOLO, C. T. Estabilidade do caldo fermentado por Xanthomonas arboricola pv pruni após armazenamento. Rev. Bras. Tec. Agroind., v. 3, p. 77-85, 2009.

BORN, K.; LANGENDORFF, V.; BOULENGUER, P. Xanthan. In: Steinbüchel, A.; Vandamme, E. J.; De Baets, S. Biopolymers. Weinheim: Wiley-VCH, 2002.

CARRINGTON, S.; ODELL, J.; FISHER, L.; MITCHELL, J.; HARTLEY, L. Polyelectrolyte behaviour of dilute xanthan solutions: salt effects on extensional rheology. Polymer, v. 37, p. 2871$2875,1996$.

DOW, J. M.; CROSSMAN, L. C.; FINDLAY, K.; HE, Y.Q.; FENG, J. X.; TANG, J. L. Biofilm dispersal in Xanthomonas campestris is controlled by cell-cell signalling and is required for full virulence to plants. Proceed. Nat. Acad. Sc. USA, v. 100, p. 10995-11000, 2003.

ERIKSSON, K. E.; PETTERSSON, B. Extracellular enzyme system utilized by fungus Sporotrichum pulverulent for the breakdown of cellulose. Separation, purification and physico-chemical characterization of five endo-1.4- $\beta$-glucanases. Europ. J. Biochem., v. 51, p. 193-206, 1975.

GARCÍA-OCHOA, F.; SANTOS, V. E.; CASAS, J. A.; GÓMEZ, E. Xanthan gum: production, recovery and properties. Biotech. Adv., v. 18, p. 549-579, 2000.

HAYWARD, A. C. The host of Xanthomonas. In J. G. Swings and E. L. Civerolo (ed.). Xanthomonas. London, United Kingdom: Chapman \& Hall, 1993.

HAYWARD, A. C. Bacteriophage sensitivity and biochemical group in Xanthomonas malvacearum. J. Gen. Microb., p. 287-298, 1964. 


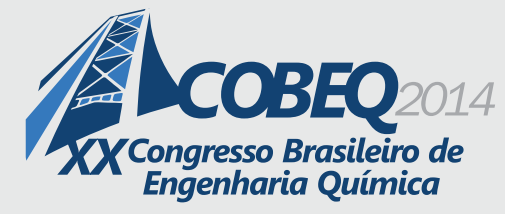

JANSSON, P. E.; KENNE, L.; LINDBERG, B. Structure of the exocellular polysaccharide from Xanthomonas campestris. Carb. Res., v. 45, p. 275-285, 1975.

KATZBAUER, B. Properties and applications of xanthan gum. Pol. Degrad. Stab., v. 59, p. 81-84, 1998.

LILLY, V. G.; WILSON, H. A.; LEACH, J. G.. Bacterial polysaccharides. App. Microb., v. 6, p. 105-108, 1958.

MILLER, G. L. Use of Dinitrosalicylic Acid Reagent for Determination of Reducing Sugar. Anal. Chem., v. 31, p. 426-428, 1959.

MOREIRA, A. S.; VENDRUSCOLO, J. L. S.; GIL-TUNES, C.; VENDRUSCOLO, C. T. Screening among 18 novel strains of Xanthomonas campestris pv pruni. Food Hydroc., v. 15, p. 469-474, 2001.

PELLETIER, E.;VIEBKE, C.; MEADOWS, J.; WILLIAMS, P. A. A rheologiacal study of the order disorder conformational transition of xanthan gum. Biopolymers, v. 59, p. 339-346, 2001.

RINAUDO, M. Relation between the molecular structure of some polysaccharides and original properties in sol and gel states. Food Hydroc., v. 15, p. 433-440, 2001.

ROSS-MURPHY, S. B.; MORRIS, V. J.; MORRIS, E. R. Molecular viscoelasticity of xanthan polysaccharide. Faraday Symp. Chem. Soc., v. 18, p. 115-129, 1983.

SLONEKER, J. H.; JEANES, A. Exocellular bacterial polysaccharide from Xanthomonas campestris NRRL B - 1459. Canad. J. Chem., v. 40, p. 2066-2071, 1962.

SUTHERLAND, I. W. Microbial polysaccharides from Gram-negative bacteria. Internat. Dairy J., v. 11, p. 663-674, 2001.

SUTHERLAND, I. W. Polysaccharases for microbial exopolysaccharides. Carb. Polymer, v. 38, p. 319-328, 1999.

SUTHERLAND, I. W. Xanthan. In: J. G. Swings \& E. I. Civerolo, Xanthomonas. London: Chapman \& Hall, 1993.

SUTHERLAND, I. W. An enzyme system hydrolyzing the polysaccharides of Xanthomonas species. J. App. Microb., v. 53, p. 385-393, 1982.

TANG, J. L.; LIU, Y. N.; BARBER, C. E.; DOW, J. M.; WOOTTON, J. C.; DANIELS, M. J. Genetic and molecular analysis of a cluster of rpf genes involved in positive regulation of synthesis of extracellular enzymes and polysaccharide in Xanthomonas campestris pathovar campestris. Mol. Gen. Genetic, v. 17, p. 226-409, 1981.

UNIVERSIDADE FEDERAL DE PELOTAS. VENDRUSCOLO, C. T.; VENDRUSCOLO, J. L. S.; 
MOREIRA, A.S. Process for preparing a xanthan biopolymer. WO/2006/047845, 2006.

VENDRUSCOLO, C. T.; MOREIRA, A. S.; SOUZA, A. S.; ZAMBIAZI, R.; SCAMPARINI, A. R. P. Heteropolysaccharide produced by Xanthomonas campestris pv pruni C24. In: NISHINARI, K. Hydrocolloids. Amsterdam: Elsevier, 1, 187-191, 2000.

WOOD, T. M.; McCRAE, S. I. The cellulase complex of Trichoderma koningii. In Symposium on Enzymatic Hidrolysis of Cellulose, p. 319-336. Helsinki: Finland, 1975. 